\author{
Franco Peña, Yolanda. \\ Estudiante doctorado, Universitat Politècnica de València, Departamento de Escultura, Grupo \\ de investigación Espacio urbano y tecnologías de género. (FPU17/00175)
}

\title{
Archivo lesbofeminista
}

\section{Lesbian-Feminist archive}

TIPO DE TRABAJO: comunicación.

PALABRAS CLAVE

Lesbianas, feminismo, arte-archivo, memoria.

KEY WORDS

Lesbians, feminism, art archive, memory.

RESUMEN

Esta comunicación expone el proyecto en construcción del archivo lésbico-feminista de la Comunidad Valenciana. Es el origen de un archivo generado a partir de la recopilación y catalogación de materiales documentales (publicaciones periódicas, libros, fotografías, vídeos, materiales gráficos, etc.) que forman parte de los diferentes colectivos LGTB y feministas junto a archivos personales. Hasta el momento no se encuentran recopilados, pero son necesarios para la construcción de una memoria colectiva de un contexto concreto. Desde hace unas décadas se ha constatado un giro en el ámbito artístico hacia la idea del archivo como práctica artística. Entender el archivo como práctica artística permite vencer al olvido mediante una narración no lineal, con múltiples lecturas. A partir de la revisión teórica y práctica de la cuestión arte-archivo se plantea un archivo vivo, flexible y en continua construcción.

Visibilizar y generar un archivo cuyo sujeto político central sean las lesbianas implica crear su genealogía. Esta acción es interesante porque hace que aparezca en un marco coherente la lucha de las mujeres y las luchas de los colectivos LGTBI, dado que todo movimiento político necesita una génesis que permita un discurso y una posición en el campo de los conocimientos situados. Visibilizar el cuerpo de prácticas, de saberes y de luchas es fundamental para revelar algo que ha quedado oculto, no solo en los saberes académicos sino también en lo social y en lo simbólico. Además, el proyecto de archivo propone generar una red con otros proyectos de características y alcances similares tanto españoles como internacionales. Estar en red implica existir.

\section{ABSTRACT}

This communication exposes the project under construction of the lesbian-feminist archive of the Comunitat Valenciana. It is the origin of an archive generated from the collection and cataloging of documentary materials (regularly printed documents, books, photographs, videos, graphic materials, etc.) that are part of the different LGTB and feminist groups plus their own personal archives. So far this material has not been collected yet. However, it is necessary for the construction of a collective memory of a specific context. For a few decades there has been a twist in the artistic field towards the idea of the archive as an artistic practice. Understanding the archive as an artistic practice allows us to overcome oblivion by means of a non-linear narrative, with multiple readings. From the theoretical and practical review of the art-archive question, a living, flexible and continuous work in progress archive is proposed.

Giving visibility and generating a file whose central political subject are lesbians means creating their genealogy. This action is interesting because it makes the women's and LGBT's movement appear in a coherent framework, since every political movement needs a genesis that allows a discourse and a position in the field of situated knowledge. Visibilizing the body of practices, knowledge and struggles is fundamental to reveal something that has been hidden, not only in academic knowledge but also in the social and symbolic ones. In addition, the archiving project proposes generating a network with other projects with similar characteristics. Being in a network implies existing. 


\section{Franco Peña, Yolanda \\ Archivo lesbofeminista}

IV Congreso INTERNACIONAL DE INVESTIGACIÓN EN ARTES VISUALES ANIAV 2019

IMAGEN [N] VISIBLE]

http://dx.doi.org/10.4995/ANIAV.2019.9582

\section{CONTENIDO}

Seis mesas, siete sillas, un asiento, un monitor, 109 revistas. Con todo ello se conforma la exposición BOLLO.doc'. El nombre de la muestra hace referencia a la documentación, al archivo bollero (lesbiano). ¿Qué interés tiene realizar una investigación en torno a este sujeto? ¿Por qué un archivo? ¿Por qué se plantea realizar la muestra en formato expositivo? En primer lugar, el interés de generar un archivo del movimiento lésbico reside en visibilizar a las lesbianas como sujeto político mediante su genealogía. Todo movimiento político necesita una génesis que permita un discurso y una posición en el campo de los conocimientos situados. Visibilizar el cuerpo de prácticas, de saberes y de luchas es fundamental para revelar algo que ha quedado oculto, no solo en los saberes académicos sino también en lo social y en lo simbólico. Por otro lado, la idea de archivo está vinculada a la compilación de documentos históricos que legitiman los acontecimientos. Sin embargo, la estrategia expositiva del archivo permite generar otras narraciones que se alejan del discurso histórico que se plantea desde el concepto tradicional de archivo. En este caso ya no estaría confinado en instituciones de acceso muy limitado y custodiado por arcontes (Guasch 2011) sino que adoptaría una estrategia de translucidez. Esta idea de translucidez de la que habla Haizea Barcenilla (2016) estaría relacionada con el equilibrio entre los conceptos de visibilidad y ocultación. Está presente la visibilidad por el hecho de ocupar el espacio público y, al mismo tiempo, mantiene una cierta ocultación ya que el archivo se muestra expuesto por fragmentos (Garazi Ansa, 2017).

Desde finales de 1960 hasta la actualidad hay un "giro" hacia la consideración de la obra de arte "en tanto que archivo" o "como archivo" en el que se comparte un interés común por la memoria, tanto individual como cultural (Guasch 2011). Jacques Derrida publica en 1995 Mal d'archive: une impression freudienne, donde toma parte de la discusión sobre el paradigma del archivo. Se podría decir que en 1998 se realizó el primer proyecto curatorial entorno al arte-archivo. En el catálogo de la exposición Deep Storage. Collecting, Storing, and Archiving in Art Benjamin Buchloh planteó el paradigma del archivo en el arte contemporáneo y analizó los proyectos de artistas europeos de los años 70 cuya temática giraba en torno a la figura del archivo. Son numerosas las exposiciones y seminarios que se han realizado sobre esta temática: Después de Deep Storage (1998) tenemos Voilà. Le monde dans la tête (2000), Culturas de archivo (I y II) (2002, 2005), The Visual Archive: History, Evidence and Make Believe (2004), Classified Materials: Accumulations, Archives, Artists (2005), Registros Imposibles. El mal de archivo (2005), Archive Fever. Uses of Document in Contemporay Art (2008), Curating Degree Zero Archive (2008), Memoria y olvidos del archivo (2010) y Arte-Archivos: América Latina y otras geografías (2010).

Las lesbianas sufren una doble discriminación a nivel jurídico, social y político dentro del sistema capitalista y patriarcal. La historia de las mujeres siempre ha permanecido invisibilizada y relegada al olvido, siendo el espacio público vetado para éstas (Fernández y Fumero, 2018). Empar Pineda ${ }^{2}$ dice "en época de Franco las lesbianas no existíamos", ya que "no se concebía que pudiera haber sexo entre dos mujeres sin ningún hombre de por medio". Esta invisibilización tiene unas consecuencias muy graves en relación a la necesidad de referentes para la construcción de la identidad. A finales de los años 70 comienzan en España a organizarse los colectivos LGTBI. Las lesbianas participan activamente desde la doble militancia, por una parte, con los grupos de homosexuales y, por otro lado, con el movimiento feminista.

Visibilizar y generar un archivo cuyo sujeto político central sean las lesbianas implica crear su genealogía. Esta acción es interesante porque hace que aparezca en un marco coherente la lucha de las mujeres y las luchas de los colectivos LGTBI, dado que todo movimiento político necesita una génesis que permita un discurso y una posición en el campo de los conocimientos situados. Visibilizar el cuerpo de prácticas, de saberes y de luchas es fundamental para revelar algo que ha quedado oculto, no solo en los saberes académicos sino también en lo social y en lo simbólico. Además, el proyecto de archivo propone generar una red con ot ros proyectos de características y alcances similares tanto españoles como internacionales. Estar en red implica existir. Actualmente existen diversos archivos feministas e identidas LGTB en activo como son: Sexual Citizenship, Oral History, And The Archive In 1970s Central And Eastern Europe; Archivo T/Genderhacker; Fons Identitats Trans i Gènere a la Biblioteca Nou Barris; Fons Feminista/LGTBI/Queer de la Biblioteca Josep Pons de Can Batlló; Digital Transgender Archive; Anarchivosida; ¿Archivo queer?; Gender Ar Net; Lesbian herstory archives; y otros.

La investigación tiene como objetivo primero constituir el origen de un archivo generado a partir de la recopilación y catalogación de materiales documentales (publicaciones periódicas, libros, fotografías, vídeos, materiales gráficos, etc.) que forman parte de los diferentes colectivos LGTB y feministas junto a archivos personales. De igual modo, el segundo objetivo es revisar otros archivos existentes para analizar cuáles son sus técnicas de archivación y documentación y distinguir la más adecuada.

En la investigación realizada tiene un papel importante las relaciones entre arte, archivo y lesbo-feminismo. Teniendo en cuenta que el punto de partida es la práctica artística, la confluencia de distintos ámbitos hacen que esta investigación adopte una metodología interdisciplinar.

En primer lugar, la cuestión ontológica de la investigación es el sujeto lésbico-feminista. El posicionamiento epistemológico que se adopta está relacionado con unos valores de interactuación entre sujeto investigador y objeto investigado que estudian el marco de las estructuras sociales. Por último, a nivel metodológico el conocimiento surge y se modifica a lo largo del proceso de la investigación. En cuanto al proceso de investigación se encuentran dificultades a la hora de abordar el estudio, debido a las lagunas existentes en la investigación sobre el movimiento y sobre las identidades lésbicas en relación al espacio ya que no existen centros de documentación en nuestro contexto. Por una parte, está la ausencia de análisis sobre las organizaciones y sus activistas y por otra está la invisibilidad en los estudios sobre movimientos afines, como el movimiento feminista o el LGTB.

\footnotetext{
${ }^{1}$ Exposición inaugurada en junio de 2018 en el contexto de las Residencias para artistas locales de la Concejalía de Juventud de Valencia.

${ }^{2}$ https://www.elperiodico.com/es/barcelona/20170627/para-franco-las-lesbianas-no-existiamos-6131320
} 


\section{Franco Peña, Yolanda \\ Archivo lesbofeminista}

IV Congreso INTERNACIONAL DE INVESTIGACIÓN EN ARTES VISUALES ANIAV 2019

IMAGEN [N] VISIBLE]

http://dx.doi.org/10.4995/ANIAV.2019.9582

Todo intento de construir una historia lesbiana, sea sociológica o histórica, conlleva enfrentarse a la erradicación de las lesbianas que se ha hecho mediante silencios, falsas representaciones y prejuicios, lo que presenta obstáculos importantes para una investigación y escritura histórica. ¿Cómo se puede reconstruir una historia a partir de la evidencia de que va a ser parcial, está ausente, oculta, negada, manipulada, trivializada y por tanto suprimida? - Adrianne Rich (1983)

En este sentido, en relación a la recogida de datos se busca la literatura secundaria en el material personal y colectivo de personas lgtb (colecciones particulares de libros, documentos, recortes de prensa, publicaciones, carteles, fotografías, cartas o apuntes $p$ ersonales) que ayudan a discernir las cuestiones planteadas en esta investigación. En relación a la recogida de datos Gracia Trujillo, en Deseo y resistencia (2008), habla sobre la difícil búsqueda de las fuentes. Habla de las mismas como inexistentes, dispersas, perdidas y desorganizadas. El hecho de que no haya un archivo donde consultar la información dificulta la investigación. Trujillo alude esta ausencia total o parcial de rastros documentales a la dinámica de acción colectiva: al disolverse los colectivos con ellos se pierden sus fuentes. "Muchos de estos documentos son producto de la inmediatez o la urgencia de la acción colectiva" (Trujillo, 2008). Además de revisar la literatura secundaria se pretende llevar a cabo el análisis de los discursos identitarios del movimiento lesbiano que aparecen en las fuentes primarias producidas por sus organizaciones más importantes (revistas, panfletos, carteles, documentos internos, ponencias, actas de congresos).
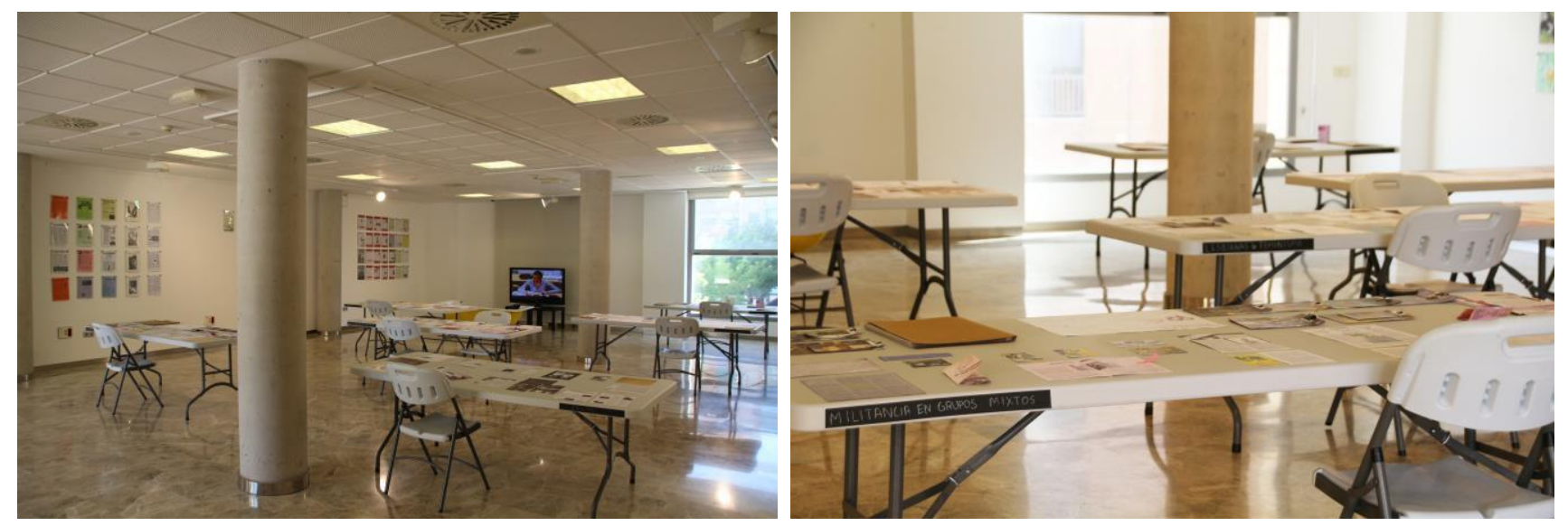

Figura 1 y 2. Imágenes de la exposición BOLLO.doc (2018)

Este archivo supone un aspecto novedoso en cuanto a que en España no se conoce ningún archivo lésbico e internacionalmente hay muy pocos.

El proceso de búsqueda de la documentación se ha centrado en el archivo de la asociación Lambda. Gran parte de la información encontrada es del contenido en las revistas publicadas del colectivo. Las revistas son Plomàs, Paper Gai, Papers Gais, Regulg, Ell full gai, Veus de llibertat, Identitats, Peres\&Pomes, Siluetas y DecideT. Analizar el colectivo de lesbianas a partir de los artículos publicados en las revistas es interesante pues permite extraer información sobre las cuestiones relevantes de cada contexto y también darse cuenta de la ínfima representación de estas dentro del colectivo mixto. Después se decidió incorporar también otros documentos como pegatinas, vídeos de conferencias, carteles y fotografías analógicas de diversas manifestaciones yencuentros.

En la exposición se mostraban seis grupos de documentación en diferentes mesas que contenían copias de los documentos. También se contó con dos de las ponencias grabadas del primer encuentro estatal de lesbianas celebrado en Madrid en 2001. Por último, todas las publicaciones periódicas se expusieron cronológicamente en las paredes de la sala.

En la exposición se expusieron las revistas en las paredes de la sala por orden cronológico y, por otro lado, la documentación extraída (escaneada e impresa) se encontraba en mesas. Se decidió organizar toda la información recopilada por temas: Militancia en grupos mixtos, Redes lésbicas, Lesbianas y feministas, Salud, (In)visibilidad, Cultura y actividades. Y a su vez cada uno de estos temas contiene otros más específicos:

En la mesa llamada Militancia en grupos mixtos encontramos documentación de las primeras agrupaciones de homosexuales y la implicación de algunas mujeres lesbianas dentro de estos colectivos (Front d'Alliberament Homosexual al País Valencià, Movimient per l'Alliberament Sexual Moviment per l'Alliberament Gai al País Valencià), donde se evidencian cuestiones relacionadas con el machismo. Por otra parte, se han agrupado artículos y recortes de prensa donde se muestran las alianzas políticas y la lucha por los derechos LGTB a nivel jurídico.

La mesa Redes lésbicas incluye una serie de documentos que muestran las relaciones entre los diferentes grupos de lesbianas en el País Valencià con el resto de agrupaciones en España. Por ejemplo, en Valencia el Colectivo Feminista de Lesbianas (Casa de la Dona) 
organiza en 1989 un Encuentro de lesbianas en el Saler. Después desde el 2002 al 2005 hay cinco encuentros organizados por el Grup de Lesbianes del Col-lectiu Lambda. Por otro lado, a nivel nacional se organizan las Jornadas Estatales de Politicas Lésbicas (FELG). A esta mesa la acompaña un monitor donde se pueden ver las ponencias realizadas en las Jornadas Lésbicas de 2003 con Jennifer Quiles y Meri Torras, donde debaten sobre la visibilidad lésbica.

En la mesa sobre la (In)visibilidad encontramos siete carpetas que contienen documentación en relación a referentes de mujeres lesbianas abiertamente visibles; la presencia de éstas en las revistas de grupos mixtos; una tercera carpeta aborda la cuestión del trabajo, con artículos relacionados con el despido de lesbianas de su puesto de trabajo por su orientación sexual; otra carpeta muestra algunas estrategias de visibilidad, como fotografías sobre acciones performáticas, también la creación de nuevos grupos de lesbianas, la reapropiación de insultos y el outing a través de la literatura; otras dos carpetas tratarían la cuestión de la lesbofobia interiorizada y la invisibilidad social; y por último contaríamos con una carpeta con artículos que plantean los estereotipos y la crítica a esa forma de etiquetaje social. Lo he modificado un poco

La mesa Lesbianas y feministas está compuesta por artículos escritos por las agrupaciones de lesbianas; cartas dirigidas al grupo de lesbianas de Lambda; comunicaciones en jornadas estatales; programa de seminario; actividades en torno al 8 de marzo, artículos sobre teóricas como Monique Wittig y activistas como Angie Simonis o Gretel Ammann. Además, también se recoge documentación de otras agrupaciones feministas.

En la mesa sobre salud encontramos carteles, folletos y trípticos sobre la prevención enfermedades por transmisión sexual. Así como artículos sobre el SIDA y el lesbianismo y también hay fotografías de mujeres lesbianas del grupo Stop Sida.

Finalmente, en la mesa Cultura y actividades se muestran carteles de las actividades realizadas por el grupo de lesbianas, la agenda con todas las noticias relevantes, un listado de entrevistas a referentes LGTB, poemas, recortes de la cartelera y listados de bibliografía lésbica.
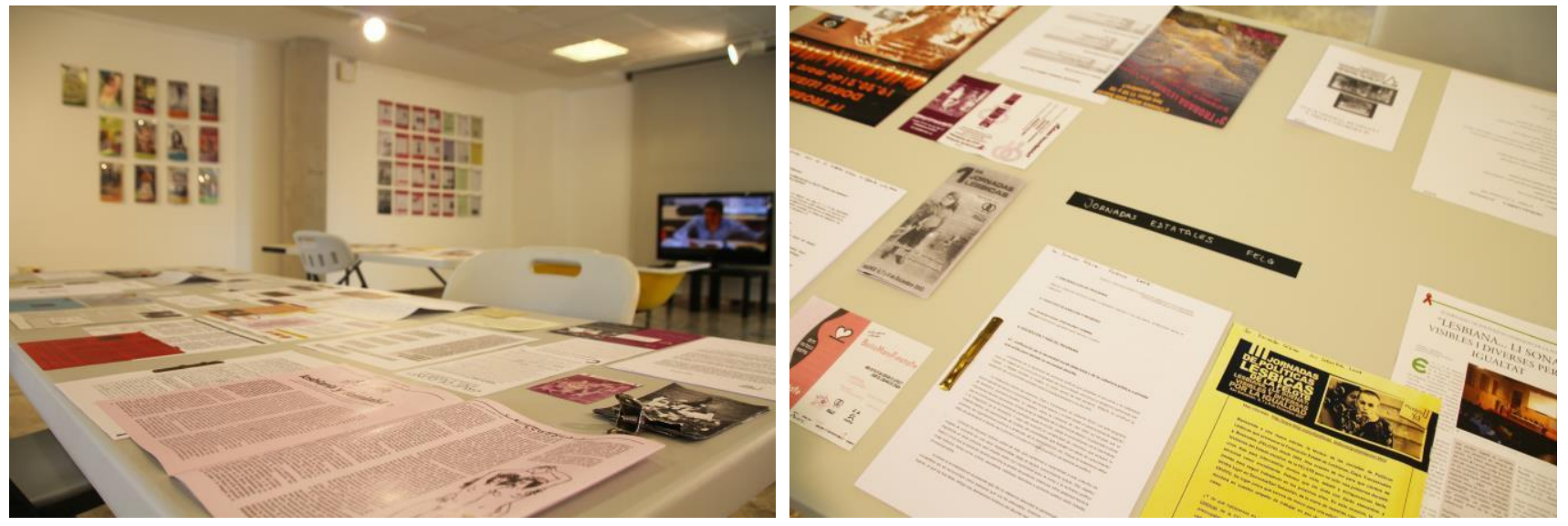

Figura 3 y 4. Imágenes de la exposición BOLLO.doc (2018)
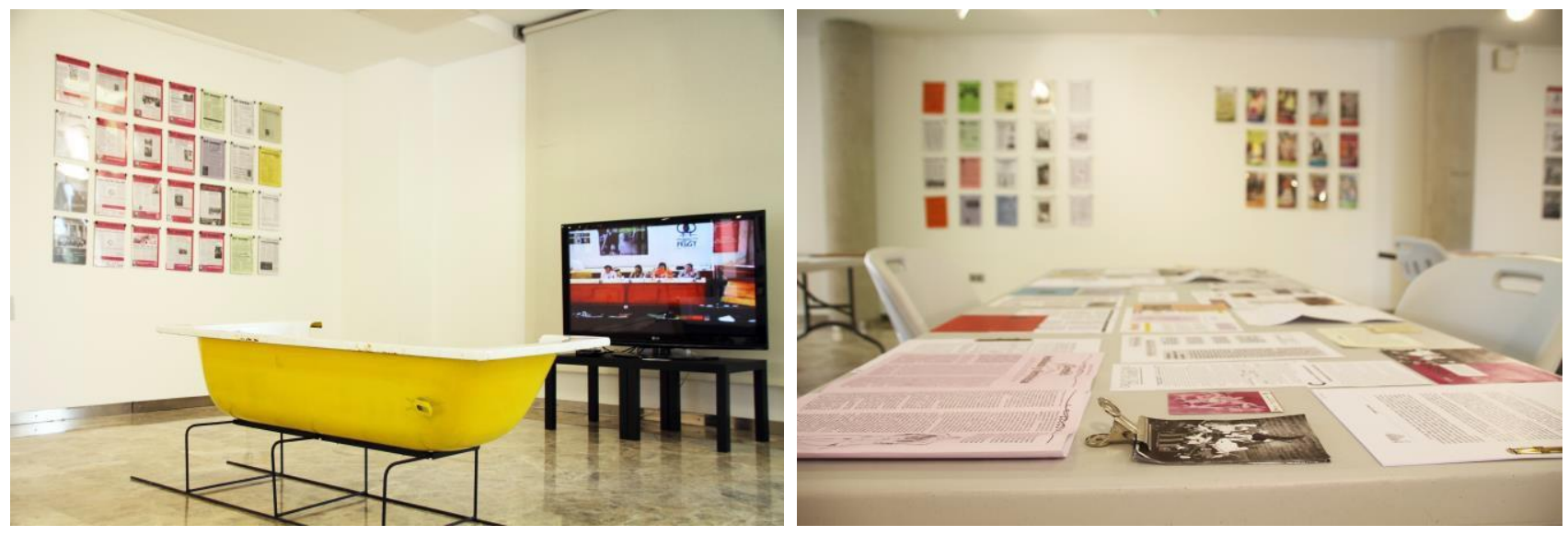

Figura 5 y 6. Imágenes de la exposición BOLLO.doc (2018) 


\section{El archivo lésbico digital}

La realización de este proyecto ha permitido generar el germen de un archivo lesbiano del País Valencià. Así pues, entendemos el archivo como práctica artística que permite vencer al olvido mediante una narración no lineal, con múltiples lecturas. No obstante, este proyecto está abierto a futuras investigaciones. Una posible línea de trabajo a desarrollar es realizar un archivo lésbico digital. Esto permitiría que la genealogía del movimiento lésbico fuera accesible a todos.

Sin embargo, tras la revisión teórica y práctica de la cuestión arte-archivo se plantea realizar un archivo vivo, flexible y en continua construcción. Además, tenemos en cuenta que el poder del archivo reside en saber cómo clasificar y ordenar la documentación para que esta sea accesible. Así pues, nos han surgido diferentes preguntas. ¿Cómo romper los viejos modelos jerárquicos con un archivo digital? ¿Se deben aplicar estrategias de clasificación y ordenación específicas? ¿Cómo subvertir la propia lógica del archivo y que a su vez pueda ser una herramienta para la construcción de una memoria colectiva de un contexto concreto?

\section{FUENTES REFERENCIALES}

Barcenilla García, H. (2016). Rompe la ventana: Exposición y ocultación en Exhibition 19 de Señora Polaroiska. En La imagen translúcida en los mundos hispánicos. Bruxelles: Orbis Tertius.

Blasco Gallardo, J (2010). Ceci n'est pas une archive. En Memorias y olvidos del archivo. Madrid: Lampreave.

Buchloh, B. (1999a). Atlas/Archive. The Optic of Walter Benjamin, vol. 3. London: Black Dog Pub.

Buchloh, B. (1999b). Gerhard Richter's Atlas: The Anomic Archive. October 88.

Derrida, J. (1997). Mal de archivo. Una impresión freudiana. Madrid: Trotta.

Fernández Herraiz, M. y Fumero, K. (2018). Lesbianas, así somos. Madrid: LoQueNoExiste.

Foster, H. (2004). Archivos y utopías en el arte contemporáneo. En Resistencia. Tercer Simposio Internacional sobre Teoría del Arte Contemporáneo. México: Patronato de Arte Contemporáneo.

Foucault, M. (2009). La arqueología del saber. Madrid: Siglo XXI.

Ansa, G. (2017). Análisis del archivo como método para la elaboración y transmisión de nuevos discursos históricos a través del caso de estudio Re.Act.Feminism \#2: A performing archive. Leioa: AusArt UPV/EHU.

Giunta, A. (2010). Archivos. Políticas del conocimiento en el arte de América Latina. Errata. Revista de Artes Visuales, 1.

Guasch, A. M. (2005). Los lugares de la memoria: el arte de archivar y recordar. Materia, 5.

Guasch, A. M. (2011). Arte y Archivo, 1920-2010. Genealogías, tipologías y discontinuidades. Madrid: Akal.

Kozak, C. (2012). Tecnopoéticas argentinas. Archivo blando de arte y tecnología. Buenos Aires: Caja Negra. Merewether, Charles (2006). The archive. London/Cambridge, Mass.: Whitechapel/MIT Press.

Viñuales, O. (1999). Identidades lésbicas. Barcelona: Bellaterra.

Viñuales, O. (2002). Lesbofobia. Barcelona: Bellaterra.

Osthoff, S. (2006). Performing the Archive: The Transformation of the Archive in Contemporary Art from Repository of Documents to Art Medium, New York: Atropos Press, 2009.

Rich, A. (1983). Mujeres y honor: algunas notas sobre el mentir. En Sobre mentiras, secretos y silencios. Barcelona: Icaria.

Rolnik, S. (2010). Furor de archivo. Estudios visuales, 7.

Schaffner, I. (1998). "Digging back into 'Deep Storage'”, Deep Storage: Collecting, Stor-ing and Archiving in Art. New York: Prestel.

Sekula, A. (1984). On the Invention of Photographic Meaning. Thinking Photography. London: Macmillan. 
Sekula, A. (2003). El cuerpo y el archivo. En G. Picazo y J. Ribalta (eds.), Indiferencia y singularidad. La fotografía en el pensamiento artístico contemporáneo. Barcelona: Gustavo Gili.

Sondergaard, M. (2009). Re_Action: The Digital Archive Experience. Renegotiating the Competences of the Archive an the (Art) Museum in the 21st Century. Copenhague: Aalborg University Press.

Sturken, M. (1999). Reclaiming the archive. Art, technology, and cultural memory. En D. Ross et al., Seeing Time. Selections from the Pamela and Richard Kramlich Collection of Media Art. California: San Francisco Museum of Modern Art.

Trujillo, G. (2008). Deseo y resistencia: Treinta años de movilización lesbiana en el Estado español (1977-2007). Barcelona: Egales.

Zweite, A. (2005). La propuesta de Bernd y Hilla Becher sobre una forma de mirar: Diez ideas clave. Tipologías. Bernd y Hilla Becher. Madrid: Fundación Telefónica. 